\title{
Retraction Note: Influence of soil rock mixture in mountain area based on machine learning and psychological intervention of left-behind children
}

\section{Pengcheng Yan ${ }^{1,2}$}

Published online: 22 November 2021

C) Saudi Society for Geosciences 2021

Retraction Note: Arabian Journal of Geosciences (2021) 14: 1560 https://doi.org/10.1007/s12517-021-07933-3

The Editor-in-Chief and the Publisher have retracted this article because the content of this article is nonsensical. The peer review process was not carried out in accordance with the Publisher's peer review policy. The author has not responded to correspondence regarding this retraction.

The original article can be found online at https://doi.org/10.1007/ s12517-021-07933-3

Pengcheng Yan

yanpengcheng7474@126.com

1 Xi'an Jiaotong University, Xi' an, Shaanxi, China

2 Xianyang Normal University, XianYang, Shaanxi, China 